\title{
Um imaginário pós-industrial? \\ A popularização do patrimônio industrial no Ruhr e a representação de sua identidade regional
}

\author{
A post-industrial mindscape? \\ The popularization of industrial heritage in the Ruhr \\ and the representation of its regional identity \\ Stefan Berger e Christian Wicke \\ Autores convidados
}

\section{Introdução}

História pública e construção de identidade desfrutam de uma relação simbiótica, e essa relação, nos últimos anos, tem sido fomentada em todo o mun-

Stefan Berger é professor de História Social e diretor do Instituto de Movimentos Sociais da RuhrUniversitaet Bochum, além de diretor da Fundação Biblioteca do Ruhr e da Casa da História do Ruhr (stefan.berger@rub.de).

Christian Wicke é pesquisador associado do Instituto de Movimentos Sociais da Ruhr-Universitaet Bochum, e pesquisador visitante do ANU (Australian National University) Center for European Studies (Christian.Wicke@rub.de).

Este texto foi traduzido do inglês por Dora Rocha. 
do. Embora tal fato tenha sido explorado em estudos sobre o nacionalismo, é interessante, além disso, observar mecanismos similares no nível regional. Este artigo enfocará assim, particularmente, a representação da identidade regional ao longo da transição em curso da região do Ruhr, na Alemanha, para uma paisagem pós-industrial. ${ }^{1}$

É interessante observar que, diferentemente de outras regiões da Alemanha, a gênese do Ruhr não se encontra na geopolítica pré-moderna, e sim na produção industrial de carvão e aço que levou à urbanização da região no século XIX. ${ }^{2}$ Assim, a região só passou efetivamente a existir através da industrialização. O conceito do Ruhr como uma região distinta emergiu muito mais tarde, no período entre guerras. ${ }^{3}$ Ao longo de sua desindustrialização, na segunda metade do século XX e início do século XXI, a herança industrial passou a ter um papel essencial no limitado repertório de identidade do Ruhr. De fato, é difícil pensar em alguma outra região urbana do mundo em que o patrimônio industrial tenha assumido um papel tão significativo na representação pública.

Nenhuma outra região da Alemanha no século XX foi tão importante economicamente quanto o Ruhr. A mudança estrutural da indústria para a pós-indústria na segunda metade do século foi dirigida e coordenada por empresas, particularmente a Ruhrkohle AG (RAG), por grandes companhias siderúrgicas, como a Thyssen- Krupp, por sindicatos e por representantes de nível comunal, estadual e federal. Foi um exemplo fundamental daquilo que, especialmente fora da Alemanha, foi descrito como capitalismo renano (Goch, 2002; Farrenkopf, 2009). Essa mudança estrutural levantou a questão do que fazer com as relíquias da mineração de carvão e da indústria do aço. Mais fundamentalmente, levantou a questão da sustentabilidade da identidade regional e, portanto, de sua representação histórica.

O patrimônio industrial foi "descoberto" na República Federal da Alemanha na década de 1960, graças às iniciativas de artistas, intelectuais e cidadãos interessados, que assumiram um papel proeminente na preservação de alguns marcos icônicos da paisagem industrial do Ruhr. Desde então sítios do patrimônio industrial passaram a funcionar como pontes de memória entre "o que realmente aconteceu" durante a era industrial e o que hoje, no início da era pós-industrial da região, é publicamente representado como industrial e também como atrativo. ${ }^{4}$ Com mais de 3.500 monumentos industriais protegidos, ${ }^{5} \mathrm{o}$ estado alemão da Renânia do Norte-Vestfália hoje se apresenta como situado entre relíquias medievais e modernas: "Quando você ouve falar na Renânia do NorteVestfália, você pensa na Catedral de Colônia, um importante monumento da Alemanha. E nas 'catedrais da indústria', como Zollverein, uma mina de carvão que se transformou em Patrimônio da Humanidade."6 Além de Zollverein, em Essen, que ocupa posição central, o "horizonte mental” da Metrópole do Ruhr 
inclui dúzias e dúzias de itens da herança industrial, destacando-se os altos-fornos do Landschaftspark de Duisburg (uma antiga fundição de aço da Thyssen), o Gasômetro (um grande depósito de gás em Oberhausen), o Tetraedro de Bottrop (uma torre com plataformas para observação em forma de tetraedro, no topo de um monte de entulho próximo a uma mina de carvão), o castelo d'água no Westpark de Bochum (local de uma fundição de aço histórica), e a Torre em U do prédio de uma antiga cervejaria em Dortmund. O passado industrial tornou-se o elemento-chave da percepção pública do Ruhr.

Em termos de patrimônio industrial, o Ruhr pode portanto ser visto na Alemanha e no mundo como uma região paradigmática. Geograficamente, esse "ente urbano" assume a forma de uma cidade descentralizada, mais do que de uma típica região (Reicher et al., 2011). A transformação socioeconômica desse emaranhado policêntrico que possui mais de 5 milhões de habitantes facilitou a organização de instituições educacionais e culturais, bem como a renaturalização daquilo que do contrário se teria tornado um cemitério industrial, e talvez levado a uma desurbanização de partes mais extensas do Ruhr. Os sítios do patrimônio industrial em certa medida resumem essa fé existencial na cultura e na natureza da era pós-industrial, e a esperança de que o Ruhr reconquiste sua centralidade econômica na Alemanha e na Europa na idade digital. A construção do patrimônio industrial no Ruhr, entretanto, pode também ser analisada contra o pano de fundo do boom da história pública, que se concentrou principalmente na representação nacional. ${ }^{7}$

Este panorama bastante conciso dos mais importantes desdobramentos históricos do patrimônio industrial no Ruhr será estruturado em três etapas: as origens do patrimônio industrial, a consolidação do patrimônio industrial e as tendências e debates recentes.

\section{As origens do patrimônio industrial no Ruhr}

A despeito do fato de que desde 1907 a Deutsche Werkbund (Federação Alemã do Trabalho) já houvesse tratado intensamente de questões de desenho industrial, o historiador da arte Tilmann Buddensieg pode ser considerado o criador do termo alemão Industriekultur, do qual muitas outras línguas europeias não possuem conceitualização equivalente. Enquanto Buddensieg, em seu trabalho datado de 1979, se voltou basicamente para a cultura industrial e a forma estética, o cientista cultural Hermann Glaser, na década de 1980, estendeu o conceito de Industriekultur, nele incluindo o mundo histórico da modernidade industrial (Glaser, 1981). Esses esforços estavam ligados à pesquisa de historiadores da vida cotidiana, como Lutz Niethammer, que procurou investigar o povo e 
suas experiências 'ordinárias', cotidianas. O fundador e diretor do Museu do Ruhr, Ulrich Borsdorf, tentou associar conceitual e praticamente a conservação de monumentos com a cultura histórica do cotidiano (Geschichtskultur) (Borsdorf, 2000). Afinal Borsdorf materializou essa concepção redesenhando o Museu do Ruhr, que abriu as portas em Zollverein em 2008. Publicações como Leben vor Ort, de Franz-Josef Brüggemaier, de 1983, e o Hochlarmarker Lesebuch, de 1981, foram parte desse reconhecimento da dimensão cotidiana do patrimônio industrial, que se centrou predominantemente nos mineiros e suas famílias.

A Industriekultur, como aparece nas numerosas definições do conceito, está intimamente conectada com o espaço industrial, ou seja, com as empresas, os espaços urbanos e a infraestrutura que determinaram a vida cotidiana de milhões de pessoas durante a modernidade industrial. Não surpreende, portanto, que a literatura sobre o patrimônio industrial na Alemanha tenha sido fortemente multidisciplinar, envolvendo urbanistas, arquitetos, curadores, museólogos, geógrafos, sociólogos, cientistas políticos e historiadores.

Os engenheiros alemães expressaram entusiasmo pelo progresso tecnológico desde o início do século $\mathrm{XX}$, quando novos tipos de monumentos foram estabelecidos como reconhecimento do rápido crescimento industrial do país. Como foi fortemente simbolizado pela criação do Museu Alemão na capital da Baviera, Munique, em $1903,{ }^{8}$ a divulgação do progresso tecnológico foi então em grande medida motivada pelas preocupações nacionais da "nação atrasada", que pouco tempo antes havia começado a lutar por seu "justo" lugar entre as grandes potências europeias (Berger, 2004). Durante o Império Alemão o Ruhr tornou-se um dos centros industriais da Alemanha. Após a Primeira Guerra Mundial, tornou-se um símbolo do desejo da Alemanha de se recuperar e se tornar mais uma vez a economia mais importante da Europa. A extensão do famoso complexo da mina de carvão de Zollverein em Essen, hoje Patrimônio da Humanidade da Unesco e a mais importante atração turística do Ruhr, ${ }^{9}$ pode ser vista, com sua arquitetura representativa e imponente desenhada por arquitetos influenciados pela Bauhaus, como um símbolo do desejo de tornar a Alemanha grande novamente. Durante esse período, também foi inaugurado o Museu da Mineração Alemã na cidade de Bochum, no Ruhr. ${ }^{10} \mathrm{~A}$ região produtora de carvão e aço entre os rios Ruhr, Reno e Emscher tornou-se então conhecida como o motor do crescimento econômico da nação.

Foi apenas com o declínio industrial que a era do patrimônio industrial se iniciou. Sugerimos situar o ponto de fuga da perspectiva histórica sobre o patrimônio industrial do Ruhr em 1969, quando a casa de máquinas da mina de carvão Zeche Zollern II/IV, em Dortmund, foi reconhecida e protegida como um monumento industrial. Esse edifício art nouveau de Bruno Möhring ainda é um dos mais importantes edifícios industriais considerados patrimônio na Alemanha. A peti- 
ção ao governador da Renânia do Norte-Vestfália para conservá-lo foi lançada predominantemente por artistas, arquitetos e historiadores da arte, assim como pelo historiador e intelectual regional Wolfgang Köllmann. O interesse subsequente de artistas e historiadores da arte pelo patrimônio industrial continuou a ser um elemento essencial não apenas para a preservação dos monumentos industriais, mas também para o design e, em certa medida, a transformação dos resquícios industriais. Dos anos 1970 em diante a estética industrial atraiu milhões de habitantes locais e turistas. Todo verão, por uma noite, durante o Festival ExtraSchicht, os principais pontos do patrimônio industrial em todo o Ruhr tornam-se cenários de espetáculos de luz. ${ }^{11}$

Ao encararmos de uma perspectiva transnacional as origens do patrimônio industrial na Alemanha, não podemos ignorar o início do movimento da arqueologia industrial (IOM) no Reino Unido. Tratando-se da primeira nação industrializada, historiadores e arqueólogos amadores do Reino Unido ficaram preocupados com a destruição de seu patrimônio nacional e consequentemente se mobilizaram para a preservação de monumentos industriais. O primeiro Congresso Internacional para a Preservação de Monumentos Industriais realizou-se em 1973 em Telford, na Inglaterra. Uma delegação acadêmica da Alemanha, incluindo o historiador da tecnologia Wolfhard Weber, também esteve presente. No momento subsequente, acadêmicos alemães, muitas vezes em cooperação com instituições públicas para a preservação do patrimônio, foram parcialmente responsáveis pela ascensão do patrimônio industrial (Neumann \& Weber, 1973; Paulinyi, 1975; Slotta, 1982).

Historiadores tecnológicos tais como Weber (1980) desenvolveram conceitos de Industriekultur, e desde 1973-4 têm sido requisitados como referências na região do Reno e na Vestafália, atuando como agentes importantes nesse processo. Associações regionais começaram a contratar conservadores, que promoveram a preservação de edifícios industriais. Atividades de relações públicas tornaram-se assim uma parte importante do movimento do patrimônio industrial no Ruhr (e outras regiões mineradoras da Alemanha).

Ainda que o IOM britânico tenha servido como um importante exemplo para os pioneiros alemães do patrimônio industrial, o impulso-chave para tornar o Ruhr $a$ região do patrimônio industrial proveio de artistas nativos, com sua intervenção seguindo uma intencionalidade estética. Hilla e Bernhard Becher, por exemplo, então baseados em Dusseldorf, começaram a fotografar objetos industriais no Ruhr a partir da década de 1960 (Becher, 1970). Suas exposições visavam antes de tudo ao conhecimento público das qualidades estéticas dos edifícios industriais (Lange, 2007). Tais perspectivas se alinhavam a uma mudança de clima ideológico e estético nos anos 1960 que transcendeu as sociedades da Europa Ocidental. Protestos estudantis e a emergência da Nova Esquerda foram ambos diri- 
gidos por - e ao mesmo tempo produziram - uma cultura histórica marxista que levava a sério o passado industrial. Ser de esquerda tornou-se moda entre as gerações mais jovens, e histórias não contadas vindas de baixo encontraram maior audiência (Reichert, 2014). Artistas, curadores do patrimônio industrial e arqueólogos industriais estavam interessados principalmente em objetos, mas a descoberta do patrimônio industrial nos anos 1960 foi também a descoberta de seres humanos, especificamente dos trabalhadores que lidavam com aqueles objetos. Sua cultura, seu mundo e seu modo de vida foram então reavivados e tornaram-se parte e parcela de relatos alternativos do passado. ${ }^{12}$ Essa nova cultura histórica, ${ }^{13}$ que articulou uma nova consciência do passado industrial no público, floresceu no Ruhr e preparou o terreno para o êxito do patrimônio industrial.

Um bom exemplo de iniciativa ligada ao patrimônio industrial vinda de baixo, que hoje ocupa um lugar importante na história oficial do Ruhr, foi o da preservação do bairro operário de Eisenheim em Oberhausen na década de 1970. Fundado em 1848, esse histórico conjunto habitacional operário ia ser demolido no início dos anos 1970. Alguns de seus moradores manifestaram resistência ao plano, e foram apoiados por um grupo de projeto liderado por Roland Günter. Günter havia feito previamente um pequeno inventário dos edifícios históricos na cidade de Oberhausen, e foi muito atuante na defesa da preservação do conjunto de Eisenheim, no que recebeu apoio do curador regional da Renânia, Günther Bochers. Quando Eisenheim teve seu patrimônio protegido em 1972, a longa luta pela modernização historicamente sensível e a manutenção de Eisenheim alcançou seu objetivo. Hoje, Eisenheim é um baluarte da representação oficial do patrimônio industrial na Renânia do Norte-Vestfália e faz parte da rota do patrimônio industrial. ${ }^{14}$ Roland Günter, antigo morador de Eisenheim, emergiu como uma figura quase mítica da geração fundadora do patrimônio industrial no Ruhr. Os próprios textos de Günter (1994 e 2001) são também um ótimo exemplo de uma narrativa dominante (não incontestada) da região do Ruhr, na qual o patrimônio industrial veio a ocupar uma posição central. Eisenheim foi um exemplo paradigmático, que foi seguido por várias outras iniciativas em todo o Ruhr. Com o objetivo de conectar essas iniciativas na região, a iniciativa de Oberhausen começou a publicar o Ruhr-Volksblatt nos anos 1970. Tudo isso representou a tendência emergente à cultura histórica democrática, que combinava pesquisa acadêmica com preservação de peças do patrimônio industrial, e produziu um significativo lugar de memória, que continua a servir como aquilo que sempre foi: um distrito onde vivem pessoas das classes trabalhadoras.

Outro exemplo fascinante de ação em prol do patrimônio industrial vinda de baixo é Zeche Carl. ${ }^{15}$ Em 1977, o padre Willi Overbeck organizou um grupo de arquitetos, conservadores do patrimônio e assistentes sociais para impedir a demolição desse complexo minerador e fundar um centro sociocultural. Eles negociaram com o Conselho de Essen e receberam o apoio do curador do estado. Simul- 
taneamente, jovens do distrito de Altenessen começaram a promover a ideia de criar um centro da juventude em Carl. As duas iniciativas se fundiram e procuraram apoio do público. Em 1978, uma associação de apoio foi fundada a fim de conduzir as negociações com o Conselho. Interessantemente, em 1979, quando foi divulgado que a cidade de Essen estava planejando destruir edifícios históricos na área a fim de construir estradas, o Initiative Zentrum Zeche Carl (IZZC) se tornou parte de um movimento mais amplo contra a destruição do distrito, que foi amplamente vitorioso. Em 1981 chegou-se a um acordo, e a cidade de Essen estava pretendendo alugar partes do complexo e a área da RAG. O IZZC teve permissão para reconstruir partes dele e pôde se mudar quatro anos depois (Brademan et al., 1989; Classen ed., 1989). Zeche Carl subsequentemente tornou-se um importante centro cultural para Essen, com um programa vibrante para uma grande diversidade de grupos sociais. O local sobreviveu à insolvência da associação IZZC, e desde 2009 está sob os cuidados da Auf Carl gemeinnützige $\mathrm{GmbH}$, uma companhia sem fins lucrativos. ${ }^{16}$

Antes de romantizar os esforços pela democracia urbana vindos de baixo, contudo, também devemos atribuir uma grande parte do êxito do movimento em prol do patrimônio industrial nos últimos 50 anos aos esforços vindos de cima, particularmente do estado da Nova Renânia-Vestfália e também - até certo ponto - das companhias industriais. Entre 1966 e 1998 a Nova Renânia-Vestfália foi governada pelos social-democratas Heinz Kühn (1966-1978) e Johannes Rau (1978-1998). Durante a "década social-democrática" da Alemanha, ou seja, os anos 1970 (Faulenbach, 2011), que começaram com o slogan de Willy Brandt “ousar mais democracia”, o patrimônio industrial não apenas legitimou a descoberta das "pessoas comuns", como serviu ao objetivo de democratizar a cultura histórica da sociedade. A Nova Renânia-Vestfália começou então a procurar sua identidade histórica no passado industrial, no qual a mineração de carvão havia desempenhado um papel decisivo. Em 1970, o governo do estado anunciou o "Programa Nova Renânia-Vestfália 1975" visando à preservação de edifícios tecnológico-históricos, incluindo chaminés e torres e casas de máquinas. O programa era uma resposta direta à retração acelerada e à morte previsível do setor minerador.

Em 1979, como parte de um programa de ação para o Ruhr, o governo Johannes Rau na Nova Renânia-Vestfália reservou dinheiro público para comprar propriedades industriais. O efeito dessa decisão sobre o desenvolvimento da região do Ruhr, tanto do ponto de vista ambiental quanto cultural, dificilmente poderá ser superestimado. Terrenos industriais abandonados puderam depois disso ser reutilizados em benefício do povo do Ruhr (Tiggemann, 2013). Após mais de 30 anos é difícil não concordar quanto ao balanço desses esforços estaduais: entre as propriedades adquiridas figura um grande número de edifí- 
cios protegidos pelo patrimônio, incluindo muitos complexos mineradores por todas as cidades do Ruhr. O fundo de terras da Nova Renânia-Vestfália (Grundstücksfond) ofereceu uma oportunidade sempre bem-vinda, particularmente diante da indefinição do futuro das propriedades, de comprar espaços industriais para uma administração intermediária, que se transformou num investimento de longo prazo na região e sua identidade. Um ano depois, em 1980, a Câmara da Nova Renânia-Vestfália aprovou a Lei de Preservação do Patrimônio Estadual (Landesdenkmalschutzgesetz), que pela primeira vez protegeu explicitamente objetos associados com o patrimônio industrial (Hassler e Kierdorf, 2000). De 1980 em diante o ministro de Planejamento Urbano da Nova Renânia-Vestfália também se tornou responsável pela proteção do patrimônio industrial nas cidades do Ruhr. Os objetos do patrimônio industrial que eram vistos como capazes de encorajar a identidade regional, e que antes haviam sido várias vezes considerados deficientes, foram favoravelmente incorporados ao novo planejamento urbano. ${ }^{17}$

Não apenas as iniciativas das comunidades e a política dos estados federais promoveram o desenvolvimento do patrimônio industrial, como a Organização Comunal Ruhr (Kommunalverband Ruhr, KVR $)^{18}$ também teve um papel extremamente importante na mudança da maneira de pensar na região. Por muito tempo a região mais industrializada do país repudiou sua imagem negativa, de ser o "elefante branco" e a "pocilga" da Alemanha. Para se contrapor a essa imagem ruim, a KVR enfatizou que a região, que havia sido tão intensamente afetada pelo carvão e pela produção de aço, ainda continha vários "pontos simpáticos". Em 1985 a KVR começou a promover uma imagem mais positiva do patrimônio industrial e do Ruhr em sua campanha Das Ruhrgebiet: Ein starkes Stück Deutschland (O Ruhr: uma parte forte da Alemanha). Campanhas posteriores perseguiram ainda mais essa ênfase positiva. Portanto não surpreende que o diretor recentemente aposentado de assuntos culturais (Kulturdezernent) da organização sucessora da KVR, a Regionalverband Ruhr (Organização Regional Ruhr, RVR), Dieter Nellen, tenha repetidamente defendido o patrimônio industrial como "uma marca geral para a NRW (Renânia do Norte-Vestafália)" (Nellen, 2001).

O forte apoio político e administrativo ao desenvolvimento do patrimônio industrial levou à criação de novos monumentos e à abertura de novos museus. Em 1969 um arquivo e um departamento de pesquisa tornaram-se parte do respeitado Museu da Mineração Alemão. Em 1973 o museu adquiriu um marco histórico quando uma maciça torre de entrada de uma mina desativada em Dortmund foi deslocada e remontada no topo do complexo do museu, que não fora localizado em um verdadeiro sítio do patrimônio industrial em 1930. O museu foi então dotado de uma maior aparência de autenticidade, como o movimento do 
patrimônio industrial exigia. A preocupação com o patrimônio industrial subsequentemente avançou cada vez mais para o centro das atividades do museu, que logo encontraria novos aliados em seu esforço para promover o Ruhr em função de seu patrimônio industrial.

Em 1979, por exemplo, foi fundado o Museu Industrial da Vestfália, com vários sítios descentralizados, incluindo também importantes complexos mineradores, como o Zeche Zollern. ${ }^{19} \mathrm{O}$ primeiro diretor do museu, Helmut Bönninghausen, que nele permaneceu por muito tempo e antes havia trabalhado no Departamento de Monumentos Técnicos (Referat für technische Denkmale) do Serviço de Proteção ao Patrimônio da Vestfália (Amt für Denkmalpflege), apoiou continuadamente o desenvolvimento do patrimônio industrial no $\mathrm{Ruhr}(\mathrm{Pa}-$ rent, 2004). Em 1984 o Museu Industrial Renano ${ }^{20}$ foi instalado numa antiga fábrica de zinco em Oberhausen (Schmenk, 2009). A história industrial estava sendo apresentada em seus sítios autênticos. Os Serviços de Proteção ao Patrimônio, tanto na Vestfália como na Renânia, estavam seriamente envolvidos na seleção dos locais dos museus. Suas considerações concentravam-se fortemente na proteção do patrimônio industrial e na preservação de monumentos técnicos, que muitas vezes não sobreviviam à reutilização de prédios históricos para novas finalidades. Os museus foram, e continuam a ser, de importância vital para a criação e a promoção do patrimônio industrial no Ruhr.

Outro ator importante na história recente do patrimônio industrial do Ruhr foi a Ruhrkohle AG, que foi fundada em 1968 como a maior companhia de mineração de carvão na Alemanha. De meados dos anos 1970 ao início da década de 1990, a companhia se beneficiou grandemente de subsídios federais. Por muitos anos a RAG se havia oposto ao movimento do patrimônio industrial, em geral reivindicando a completa demolição de antigos complexos de mineração. As áreas reabilitadas seriam, ao ver da companhia, mais úteis como centros comerciais, como novos centros de trabalho ou como núcleos residenciais (Huse, 1997). A Lei Federal de Mineração(Bundesberggesetz) de 1980 permitia explicitamente às companhias demolir edifícios existentes ou minas desativadas. Enquanto o movimento do patrimônio industrial no Ruhr já havia começado a dar os primeiros passos para redesenhar a paisagem pós-industrial, a RAG aplaudia essa autorização legal. Em vista do fato de que a manutenção dos sítios do patrimônio industrial envolve não apenas dificuldades técnicas, mas também custos assustadores, a RAG só estava querendo fazer concessões em casos excepcionais, em que os Serviços de Monumentos estavam pressionando fortemente pela realização de seus interesses. A vigorosa documentação de objetos do patrimônio industrial feita por curadores como Walter Buschmann foi vital a esse respeito (Buschmann, 1985, 1992 e 1998). Não devemos esquecer que até mesmo o sítio hoje considerado patrimônio da humanidade pela Unesco, Zollverein, teria sido 
em grande parte demolido sem as ações do movimento do patrimônio industrial em oposição à direção da RAG. ${ }^{21}$

Contudo, seguindo o longo processo de mudança na maneira de pensar na região a partir dos anos 1970, a RAG também se transformou numa importante defensora da preservação do patrimônio industrial, ainda que seu empenho continuasse a depender de interesses comerciais (vide por exemplo a demolição dos complexos de Lohberg e de Walsum) (Kleineberg, 1996). A partir dos anos 1990, a subsidiária RAG Montan Immobilien emergiu internacionalmente como a pioneira da conversão historicamente sensível dos sítios das minas, ainda que sempre dependente da locação e das oportunidades do mercado. A história não é um valor enquanto tal, pode-se argumentar, mas implica um valor de mercado que é em grande medida dependente da identidade histórica. A mudança da RAG Montan Immobilien para Zollverein e sua cooperação com a Fundação Zollverein para lançar alguns projetos lucrativos na área sugerem uma nascente relação de permuta entre o patrimônio industrial e o valor de mercado (Noll, 2009a e 2009b).

A ação da Stiftung Indusdustriedenkmalpflege und Geschichtkultur (Fundação para a Proteção do Patrimônio Industrial e Cultura Histórica), que manteve estreitas relações com a RAG, não deve ser ignorada quando ela decide conservar o patrimônio industrial como parte da cultura histórica regional mais ampla, ainda que os ambiciosos objetivos da fundação nem sempre tenham sido alcançados. Seguindo o modelo do National Trust na Grã-Bretanha, a Stiftung foi fundada no fim da década de 1980 em meio às sombras opressivas produzidas pelo fechamento de enormes complexos industriais. A fundação foi criada para pôr sob suas asas propriedades e edifícios de várias indústrias a fim de salvar companhias do altos custos da demolição. Após algumas melhorias básicas, esses sítios seriam colocados no mercado. Apenas nos casos em que a revenda não fosse possível esses sítios permaneceriam com a fundação, como aconteceu com a Hansa Cooking Plant (Ganser, 2005 e Mehrfeld, 2005 e 2009). Propriedade da Stiftung, a Hansa Cooking Plant em Dortmund, por exemplo, que passou a ser considerada patrimônio em 1998, se apresenta como uma "enorme escultura com circulação interna".22

\section{A consolidação do patrimônio industrial no Ruhr, 1989-2010}

No final do século XX, os sítios do patrimônio industrial se haviam tornado importantes emblemas interativos das cidades do Ruhr, fóruns da cultura histórica regional, sede de uma diversidade de eventos públicos e privados, e centros internacionais para encontros com um passado estrangeiro. Um dos 
eventos mais significativos na história do patrimônio industrial no Ruhr foi o IBA Emscher Park. ${ }^{23}$ Entre 1989 e 1999 o IBA dedicou-se à revitalização da parte norte do Ruhr (socioeconomicamente a parte mais fraca da região). Sobretudo nessa chamada zona de Emscher, o IBA desencadeou um esmagador programa de defesa do patrimônio industrial. Esse projeto de dez anos se estendeu por uma grande area do Ruhr, de Duisburg, a leste, até Hamm, a oeste, e de Recklinghausen, ao norte, até Bochum, ao sul. A visão do IBA combinava a regeneração do meio ambiente, da economia e da sociedade. A proteção ambiental e a proteção do patrimônio industrial formaram uma aliança. Os males da industrialização deveriam ser eliminados, e deveria ser introduzido um programa de ação estrutural para a futura viabilidade da região. Os edifícios industriais eram encarados como parte da cultura regional. O carismático administrador do IBA Emscher Park, Karl Ganser, usou seu orçamento de 5 bilhões de marcos para realizar 120 projetos de planejamento das cidades e da paisagem em 17 municipalidades do Ruhr (Reicher et al., 2011; Urban, 2008; Sack, 1999; Kilper, 1999; Ganser e Höber, 2000). ${ }^{24}$

O IBA levou a uma maior visualização e popularização do patrimônio industrial (Prossek, 2008). Os principais projetos do IBA incluíram o Gasômetro em Oberhausen, o Landschaftspark de Duisburg, o Science Park de Gelsenkirchen, e o Poço 12 de Zollverein. Uma das primeiras exposições de arte no Gasômetro, Feuer und Flamme, por exemplo, atraiu meio milhão de visitantes. O Landschaftspark de Duisburg, com seus 200 hectares da antiga fundição de Meidereich, não só se transformou num refúgio para pássaros e plantas, como também se tornou um ponto de atração para as pessoas da região e para estrangeiros: suas paredes de escalada, seu tanque para mergulho e seus palcos para música e teatro atraíram uma grande variedade de grupos sociais. Enquanto isso, Zollverein, na condição de patrimônio da humanidade da Unesco, se tornou o principal ponto de atração do Ruhr. O poder simbólico desse museu ao ar livre mundialmente famoso, que abriga um dos mais prestigiados museus regionais, o Red Dot Design Museum, o edifício SANAA da Universidade de Folkwang (projetado por Sejima And Nishizawa And Associates), o centro de arte coreográfica PACT (Performing Arts Choreographisches Zentrum NRW Tanzlandschaft Ruhr) e muitas outras instituições interessantes, não pode ser subestimado.

É importante, neste ponto, mencionar rapidamente que, paralelamente ao IBA, e vizinho ao Gasômetro, o maior shopping da Europa, com uma enorme praça de alimentação e numerosos centros de entretenimento, foi instalado na área da antiga empresa de mineração Gutehoffnungshütte. Ainda que o Centro seja hoje muito popular entre os habitantes do Ruhr e de outras regiões, ele permanece um caso extremamente controverso de planejamento urbano. $\mathrm{O}$ projeto 
pode ser interpretado como uma antecipação da tendência à comercialização do patrimônio industrial, que será discutida adiante.

Muitos sítios do patrimônio industrial no Ruhr foram explicitamente conectados a questões de identidade regional pelos responsáveis pelo IBA. Os espetáculos de luz, por exemplo, contribuíram para uma exaltação estética do patrimônio industrial e por conseguinte promoveram sua aceitação entre a população regional (Sievert, 1999). Essa grande exibição pública do patrimônio industrial tem sido desde então intimamente conectada a campanhas de imagem regional e ao marketing do Ruhr como um espaço pós-industrial em busca de revitalização. Mais que isso, ela ofereceu aos turistas estrangeiros uma imagem coerente do Ruhr. ${ }^{25}$ Não foi à toa que a partir de 1999 grandes placas marrons ao longo das estradas do Ruhr passaram a assinalar os principais objetos do patrimônio industrial. ${ }^{26}$

Visto como um todo, o IBA foi o acontecimento-chave para tornar o patrimônio industrial a característica-chave, histórica e cultural, do Ruhr. Nos anos 1990, ele também contribuiu para a conscientização da importância da dimensão imaterial do patrimônio industrial. Alimentos (currywurst), esportes (futebol) e conflitos (greves) passaram a ocupar lugar de destaque na imagem mental da região mineradora (Berger, 2008). Conceitos do Kumpel (companheirismo entre mineiros) também foram associados ao patrimônio industrial, tanto quanto os quiosques (Trinkhallen) e os bares públicos das esquinas (Eckkneipen). Além disso, o Emscher Park do IBA trouxe o patrimônio industrial mais para o centro do foco dos planejadores urbanos (Reicher, 2009).

A ideia de uma fundação nacional para um parque nacional que preservasse o patrimônio industrial no Ruhr surgiu pela primeira vez com o IBA. A ideia de um parque nacional inspirou-se no exemplo americano de Lowell, perto de Boston, que foi o primeiro parque nacional de patrimônio industrial. As municipalidades do Ruhr rejeitaram a ideia, na medida em que homens de negócios e políticos regionais temiam que um parque nacional se estendendo por toda a região restringisse seu potencial de desenvolvimento. A ideia da Rota do Patrimônio Industrial (Route der Industriekultur) emergiu como uma espécie de compromisso. Ela poderia conectar sítios do patrimônio industrial através da região, sem chegar a operar como um parque nacional. Reinhold Budde concretizou essa ideia com grande sucesso. ${ }^{27}$ Durante as discussões sobre uma fundação nacional e um parque nacional, os defensores dessas ideias chamaram a atenção para o significado do Ruhr para a Alemanha como um todo. O Ruhr foi apresentado como a região-chave e o motor do desenvolvimento econômico do Estado-Nação alemão desde 1871 e da República Federal até os anos 1970. Portanto, segundo a argumentação, a herança dessa era no Ruhr deveria ser administrada em nível nacional. Essa nacionalização da nar- 
rativa regional foi usada simultaneamente para fomentar o orgulho e o pertencimento ao Ruhr entre a população. A ideia de uma fundação nacional não foi completamente abandonada, e o futuro mostrará se ela irá prevalecer. ${ }^{28} \mathrm{Em}$ 2001 Zollverein tornou-se patrimônio da humanidade da Unesco. Isso significou que a proteção de amplo alcance do patrimônio do complexo, inclusive aquele ligado à produção do coque, fora finalmente alcançada - coisa que muitos haviam acreditado ser impossível (Buschmann, 2002; Schwarz, 2008). O curador do estado da Nova Renânia-Vestfália, Günter Borchers, já se havia referido ao potencial de Zollverein como sítio de patrimônio antes de seu fechamento em 1986. Em 1985 o ministro do Planejamento Estadual e Urbano, Christoph Zöpel, e o novo Departamento de Monumentos do estado intervieram na decisão da RAG e do Conselho de Essen de demolir o complexo. Em 1986 Zollverein passou ter seu patrimônio protegido. A agência de desenvolvimento do estado, junto com o fundo de propriedade estadual, comprou a área $\mathrm{e}$ convocou um grupo de trabalho para planejar o uso futuro daquele sítio do patrimônio. Em 1988, um ano antes do início do IBA, foi tomada a decisão de desenvolvê-lo como um sítio cultural, e foram criadas a Fundação Zollverein, bem como uma agência de desenvolvimento de Zollverein.

A primeira década do século XXI fortaleceu ainda mais a posição de patrimônio industrial na cultura histórica do Ruhr. A Rota do Patrimônio Industrial, equipada com um orçamento anual estável, foi continuamente estendida. Vinte e cinco pontos-âncora (destaques especiais do patrimônio industrial), 16 panoramas (perspectivas cênicas) da paisagem industrial do Ruhr e 13 bairros operários foram incluídos na rota. Além disso, rotas temáticas específicas e atrações típicas de verão foram instaladas ao longo dos $400 \mathrm{~km}$ do círculo da estrada e dos $700 \mathrm{~km}$ da rede de ciclovias. A mina de Ewald em Herten, fechada em $2000 \mathrm{e}$ hoje parte do Landschaftspark Hoheward, ${ }^{29}$ é um exemplo de mudança estrutural bem-sucedida, combinando patrimônio industrial com fascinantes oportunidades de lazer. A mina de Nachtigall em Witten e sua exposição fazem parte de quatro roteiros temáticos: "primórdios da industrialização", "história e estado atual do rio Ruhr", "o roteiro da mineração na Vestfália" e "o mito do Ruhr". O terreno da antiga mina de Nordstern em Gelsenkirchen foi transformado em um exemplar jardim, integrando as relíquias do passado industrial na construção da paisagem. Os antigos edifícios da central de pagamentos (Lohnhalle) servem como edifícios de escritórios para importantes companhias da região, como a Vivawest, a terceira maior empresa voltada para a habitação da Alemanha.

$\mathrm{O}$ desenho criativo dos montes de entulho transformou a paisagem industrial num conjunto geográfico único de cultura e natureza no qual a representação do patrimônio industrial está sempre presente: merecem ser mencionados Rheinelbe (como parte do circuito ciclístico do Emscher Park), Schwerin 
(formando o ponto mais alto da cidade de Castrop-Rauxel e contendo um relógio de sol que se pode percorrer), Großes Holz (com seus shows de luz e seu desenho paisagístico), Heinrich-Hildebrand Höhe (com a famosa escultura Tigre e Tartaruga), Rheinpreußen (com uma escultura maciça em forma de lâmpada de minerador), Pattberg (como parte do parque NiederRhein), Haniel (com um anfiteatro e esculturas), e Rungberg (com uma construção geométrica de seu pico e o show de luz Nachtzeichen). Os alojamentos de trabalhadores protegidos pelo patrimônio incluem, por exemplo, Flöz Dickebank (que originalmente pertencia à mina de Alma em Gelsenkirchen, onde se realizou o congresso de 1976 pela preservação dos alojamentos dos trabalhadores). O alojamento Dahlhauser Heide (de 1906-1915), que fica perto das minas de Hannover e Hannibal, aparece mais como uma vila do que um distrito da cidade de Bochum, impressão acentuada por sua arquitetura regional (Heimatstil). ${ }^{30}$

Em 2010 o Ruhr (com a cidade de Essen como sua representante) foi a Capital Europeia da Cultura. ${ }^{31}$ Ainda que a maioria dos projetos relacionados a essa condição não fosse diretamente ligada ao passado industrial, era impossível ignorar a representação do patrimônio industrial da região e a identidade regional a ele associada. A inauguração simbolicamente vigorosa do ano da capital cultural em Zollverein, declarada patrimônio da humanidade pelo Unesco, acendeu um farol de esperança para a região e sua herança industrial.

Quando o Museu do Ruhr inaugurou em Zollverein sua exposição completamente reconceitualizada sobre a região do Ruhr no início do ano de capital cultural, o passado e o patrimônio industriais foram representados com destaque entre os itens expostos. No final de 2012, o museu alcançou 1,5 milhão de visitantes por ano, e continua sendo um dos museus regionais mais visitados da Alemanha. ${ }^{32}$ Ele não é explicitamente um museu industrial, mas sua ênfase no patrimônio industrial mostra o quão importantes são os restos do passado industrial para a representação oficial da região nos dias de hoje. ${ }^{33}$

\section{Tendências e debates recentes}

O fato de o patrimônio industrial ter alcançado êxito de forma tão coesa em toda a região, e de ainda ser apoiado por importantes atores regionais, decorre em grande parte do fim socialmente aceitável e consensual da mineração na área. $\mathrm{O}$ capitalismo renano, em que impera um modelo tripartite, baseia-se na cooperação entre municipalidades, estados federais e governos federais e ainda na cooperação entre empregadores e trabalhadores. Esse modelo não funciona sem subsídios do Estado, mas evita os conflitos mais radicais bastante conhecidos de outras regiões mineradoras em declínio na Europa, como Gales do Sul 
(Berger, 2008). É verdade que um grande número de protestos e greves ocorreu dentro desse modelo, mas no final das contas ele segue o ideal de uma busca consensual do melhor resultado para todas as partes.

Muitos expoentes do patrimônio industrial do Ruhr apresentaram essa região como um modelo para outras aglomerações policêntricas em processo de desindustrialização que precisam se posicionar diante dos restos de indústrias pesadas (Ebert, 2011). Existem vários guias de viagens sobre o patrimônio industrial do Ruhr e toda uma produção literária que reforça sua incrível história de sucesso. ${ }^{34} \mathrm{~A}$ imagem do patrimônio industrial, que de patinho feio passou a santuário secular da modernidade, mudou dramaticamente no Ruhr (Suhrbier, 1997 e Sturm, 2007). A cultura do lazer no Ruhr foi cada vez mais conectada ao patrimônio industrial. A preservação do patrimônio industrial no Ruhr nas últimas décadas tornou-se cada vez mais um evento cultural: sítios servem de parques, mirantes, marcos, playgrounds, espaços para instalações artísticas e performances, museus, sedes de eventos, teatro e salas de música, e clubes de dança. Os festivais de arte como o ExtraSchicht e o hoje mundialmente conhecido Ruhrtriennale, um festival anual que usou sítios do patrimônio industrial para abrigar importantes projetos artísticos internacionais, ${ }^{35}$ atraem centenas de milhares de turistas para o "Cinturão da Ferrugem" da Alemanha. Antigas vias férreas entre os sítios produtores "renaturalizados" foram transformadas em ciclovias, e montes de entulho foram tingidos de verde para os andarilhos (Angelo, 2013). A consequente alienação de sítios do patrimônio industrial tornou-se objeto de controvérsia (Föhl, 2001 e Grütter, 2004).

Essa tendência dominante não pode ser atribuída apenas a mudanças estéticas na sociedade do final do século XX. Nem se trata apenas de fazer da necessidade uma virtude. Também existe uma explicação estrutural para essa evolução: outras regiões industriais do mundo, como as Astúrias, na Espanha, com maior diversidade de narrativas históricas que poderiam ser utilizadas publicamente para processos de construção de identidade, não precisam reverter para um repertório de identidade monocultural como o Ruhr. A representação da história do Ruhr, com sua rede comparativamente insignificante de lugares de memória pré-industriais ao longo do Hellweg, não consegue pôr de lado a poderosa narrativa industrial. Parece ser uma necessidade existencial para a identidade regional do Ruhr lembrar o passado industrial.

Em antigas regiões produtoras de carvão e aço, o conceito de patrimônio industrial está predestinado a desempenhar um papel importante em suas culturas históricas. Na busca de identidades regionais essas regiões cuidam de seu passado industrial (Füßmann, Grütter e Rüsen, 1994). Não surpreende, portanto, que administradores de museus recentemente tenham ficado alarmados ${ }^{36}$ quando a imprensa popular da Alemanha citou um antigo político conservador, Laurenz 
Meyer, que criticou o foco regional no passado industrial como um olhar muito para trás e descreveu os sítios do patrimônio industrial como "ruínas". 37

Essa grande controvérsia ainda gira em torno da questão de decidir se uma identidade regional estática baseada num reflexo permanente do patrimônio industrial talvez não possa impedir a mudança estrutural e o realinhamento mental do Ruhr. O cientista social Stefan Goch (1997) analisou a profunda construção de identidade através do patrimônio industrial do Ruhr de uma maneira positiva. Outros acadêmicos, contudo, são mais céticos e alertaram para um antiquarismo industrial paralisante que omitiria a transição para um futuro pós-industrial. Ou então apontaram para uma história do Ruhr que é muito mais antiga do que a era industrial (Heinemann, 2003; Schrumpf \& Budde (eds.), 2001; Parent, 2001; Rohe, 1984). A morte recente de Karl Albrecht, o homem mais rico da Alemanha e fundador da cadeia de supermercados Aldi, também lembrou ao povo do Ruhr que sua economia não era baseada exclusivamente nas indústrias pesadas de carvão e aço e que sua história econômica foi possivelmente mais diversificada do que o boom do patrimônio industrial foi capaz de representar. ${ }^{38}$ Os conservadores do patrimônio, porém, consideram absurda a visão de que os monumentos prejudicariam o desenvolvimento econômico: afinal, o economicamente muito bem-sucedido estado da Baviera nunca contestaria a legitimidade dos muitos palácios e castelos por razões de sustentabilidade econômica. ${ }^{39} \mathrm{Os}$ defensores do patrimônio industrial, como Delf Slotta (2001), preferem argumentar que o patrimônio industrial fornece uma fundação para locais de futuro desenvolvimento econômico.

Acompanhando o trabalho de Jörn Rüsen, não podemos ignorar a centralidade do patrimônio industrial na cultura histórica de uma antiga região mineradora como o Ruhr. Essa cultura histórica está intimamente conectada a questões de busca de sentido, autoentendimento e representação. Em outras palavras, o patrimônio industrial abre horizontes de significado para regiões (pós-)industriais. Rüsen (1998: 4) apontou um problema nesse processo: "quando as condições de vida não podem continuar a ser as mesmas do passado, a habilidade de uma sociedade para mudar depende de em que medida ela é capaz de extrair força de sua memória histórica para a transformação dessas condições. A região do Ruhr é um bom exemplo do fato de que essa mudança estrutural pode ser conscienciosamente planejada e realizada através da revisão da memória". Ao mesmo tempo, porém, não há nenhum perigo de que aquelas "condições históricas e a conexão vital atual do povo do Ruhr sumam sob bela aparência de relíquias esteticamente construídas... A sombra do esplendor estético é um passado des-historicizado".

Essa acusação é dirigida contra a crescente relação entre o patrimônio industrial e a cultura de entretenimento contemporânea. $\mathrm{O}$ "histotenimento", tal como realizado no centro alpino (com uma corrida de trenó, um passeio preso 
na corda ou uma descida de esqui numa rampa em espaço fechado) da mina de Prosper em Bottrop, próxima ao Tetraedro, e de muitas maneiras também no Centro, perto do Gasômetro, não convida as pessoas a repensar criticamente o passado industrial.

Ainda assim, mesmo que a história industrial tenha sido fundacional para o Ruhr e sua identidade regional, o conceito de Reinhart Koselleck de "camadas de tempo" (Zeitschichten) (2003) pode ser útil para romper a representação monocultural da história do Ruhr e resolver a opção ou-ou. ${ }^{40} \mathrm{O}$ passado deixou essa região com várias dessas camadas de tempo, que foram elas próprias transliteradas ao longo do tempo. Os pesquisadores ainda podem revelar essas camadas. Os palimpsestos temporais do passado do Ruhr se espraiam pelo presente, onde oferecem possibilidades para o futuro. O histórico cultural do Ruhr seria prudente em não reduzir essas camadas de tempo a uma única narrativa teleológica do passado, e sim permitir horizontes diversos de possibilidades. Afinal, a história está sempre aberta ao futuro; é exatamente esse desafio que a torna tão cativante.

Notas

1. Partes deste artigo baseiam-se em Berger (2013).

2. Para uma história geral da região do Ruhr, ver Tenfelde e Urban, eds. (2010).

3. Ver, por exemplo, Spethmann (1933); ver também Goch (2001).

4. Para o exemplo de uma antiga usina de aço da Thyssen em Duisburg, ver Hemmings e Kagel (2010).

5. Ver: http://www.mbwsv.nrw.de/stad tentwicklung/baukultur/industriekultur/ (acesso em 5 de setembro de 2014).

6. Ver http://www.nrw.de/en/north-rhi ne-westphalia/state-and-people/ (acesso em 30 de julho de 2014). Sobre a identidade regional do estado da Renânia do Norte-Vestfália, ver Cornelißen (2008).
7. Ver, por exemplo, Berger, Lorenz e Melman, eds. (2011); Berger, Eriksonas e Mycock, eds. (2008); Tilmans, Van Vree e Winter (2010); Korte e Paletschek, eds. (2012).

8. Ver: http://www.deutsches-museum.de (acesso em 5 de setembro de 2014).

9. Ver: http://www.zollverein.de (acesso em 5 de setembro de 2014); para uma "viagem fotográfica" pelo complexo, ver: http://www.archdaily.com/534996/a-phot ographic-journey-through-zollverein-a-p ost-industrial-landscape-turned-machine -age-playground/ (acesso em 5 de setembro de 2014).

10. Ver: http://www.bergbaumuseum.de (acesso em 5 de setembro de 2014).

11. Ver: http://www.extraschicht.de/ (acesso em 5 de setembro de 2014). 
12. Para a tradição alemã da historiografia nacional, ver Berger (1997). Para a história da história social, ver Kocka (2002). Para a história social dos mineiros no Ruhr, ver Tenfelde (1977). Para a história da vida cotidiana, ver Lüdke (1989). Para a história oral, ver Niethammer (1980).

13. Cultura histórica (Geschichtskultur) refere-se aqui particularmente ao trabalho de Rüsen (1994). Para a cultura histórica no Ruhr, ver Tenfelde (1996).

14. Ver: http://www.route-industrie kultur.de/ (acesso em 5 de setembro de 2014).

15. Agradecemos a Jana Golombek por sua sugestão neste caso.

16. Ver: http://www.derwesten.de/staedte/ essen/zeche-carl-konzentriert-sich-aufs-k erngeschaeft-id80098.html (acesso em 5 de setembro de 2014).

17. Para a conexão entre projeto futuro e patrimônio industrial no Ruhr, ver Dürr e Gramke eds. (1993).

18. Hoje chamada Organização Regional Ruhr (Regionalverband Ruhr, RVR). Ver: http://www2.rvr-online.de/ (acesso em 5 de setembro de 2014).

19. Hoje chamado LWL-Industriemu seum. Ver: http://www.lwl.org/LWL/ Kultur/wim/portal/ (acesso em 5 de setembro de 2014).

20. Hoje LVR-Industriemuseum. Ver: http://www.industriemuseum.lvr.de/de/st artseite.html (acesso em 5 de setembro de 2014).

21. Walter Buschmann (2002: 31-36). É interessante notar que o sindicato alemão de mineradores (IG Bergbau) alinhou-se aos diretores das indústrias de carvão contra a preservação do patrimônio industrial, por considerá-lo o coveiro de sua profissão. $\mathrm{O}$ sindicato estava ao contrário muito mais interessado na manutenção em funcionamento das minas e no emprego, e desse modo encarava a transição da mineração para o patrimônio industrial com suspeita. Apesar disso, muitos diretores, engenheiros e trabalhadores da área do Ruhr se entusiasmaram com a conservação de artefatos industriais e suas tradições. Portanto, a hostilidade unida entre sindicatos e companhias mineradoras em relação ao patrimônio industrial era de natureza estratégica. Essa relação certamente merece ser mais explorada, mas isso estaria além do escopo deste artigo.

22. Kokerei Hansa, ver: http://www. industriedenkmal-stiftung.de/docs/47299 1885334_de.php (acesso em 5 de setembro de 2014).

23. Internationale Bauausstellung Emscher Park, ver: http://www.iba.nrw. de/main.htm (acesso em 5 de setembro de 2014).

24. Sobre o turismo, ver também Hücherig (1992).

25. Para essas estratégias de imagem, ver Dittmar (2002).

26. Para a relação entre turismo e patrimônio industrial, ver Schwark ed. (2004).

27. Ver: http://www.route-industrie kultur.de/ (acesso em 5 de setembro de 2014).

28. Ver também IBA Emscher Park ed. (1999).

29. Ver: http://www.landschaftsparkhoheward.de/ (acesso em 5 de setembro de 2014).

30. Para a Rota do Patrimônio Industrial, ver também Grütter (2004).

31. Ver: http://archiv.ruhr2010.de/en/ home.html (acesso em 5 de setembro de 2014).

32. Ver Press Release, Unesco World Heritage Site Zollverein, Essen, Data, Facts and Figures, em http://www.zollverein. 
de/uploads/assets/52a05eb66954980dda00 0020/UNESCO_World_Heritage_Site_Z ollverein_Data_Facts_Figures_en_.pdff (acesso em 5 de setembro de $201 \overline{4}$ ).

33. Para uma comparação dos museus industriais na Alemanha, ver Röckner (2009).

34. Dois entre muitos exemplos são Bosch (2005) e Buschmann (1993).

35. Ver: https://www.ruhrtriennale.de/de/ (acesso em 5 de setembro de 2014).

36. Ver: http://www.bild.de/regional/ ruhrgebiet/kultur/unsere-industrie-kultu r-ist-einzigartig-37028462.bild.html (acesso em 5 de setembro de 2014).

37. Ver: http://www.bild.de/regional/ ruhrgebiet/politiker/man-denkt-doch-hie

\section{Referências bibliográficas}

ANGELO, Hillary, More than exception: categories and the problem of "nature" in the Ruhr. In: Moving the Social 50, 2013, pp. 7-24.

BECHER, Bernd und Hilla. Anonyme Skulpturen. Düsseldorf, 1970.

BERGER, Stefan. The search for normality: national identity and historical consciousness in Germany since 1800. Oxford and New York, 1997.

Oxford, 2004.

. Von "Landschaften des Geistes" zu "Geisterlandschaften": Identitätsbildungen und der Umgang mit dem industriekulturellen Erbe im südwalisischen Kohlerevier. In: Mitteilungsblatt des Instituts für soziale Bewegungen 39, 2008, pp. 49-65. r-kann-man-nur-ruinen-besichtigen-370 14162.bild.html (acesso em 5 de setembro de 2014).

38. Ver: http://www.ruhrnachrichten.de/ nachrichten/wirtschaft/aktuelles bericht e/Die-Urspruenge-von-Aldi-Gut-100-Jah re-Familienunternehmen-Albrecht;art31 8,2429554 (acesso em 5 de setembro de 2014).

39. Agradecemos a Walter Buschmann por essa sugestão.

40. Ver também Kerstin Barndt, Layers of time: industrial ruins and exhibitionary temporalities: https://www.lsa.umich. edu/UMICH/german/Home/People/Barn dtPMLA.pdf (acesso em 5 de setembro de 2014).

- Industriekultur und Strukturwandel in Deutschen Bergbauregionen nach 1945. In: TENFELDE, Klaus; BERGER, Stefan \& SEIDEL, HansChristoph (eds.). Geschichte des Deutschen Bergbaus, vol 4 (ed. by ZIEGLER, Dieter), Rohstoffgewinnung im Strukturwandel: Der Deutsche Bergbau im 20. Fahrhundert. Münster, 2013, pp. 571-601.

-——, ERIKSONAS, Linas \& MYCOCK, Andrew Mycock (eds.). Narrating the nation: representations in history, media and the arts. New York and Oxford, 2008.

LORENZ, Chris \& and MELMAN, Billie (eds.). Popularizing national pasts: 1800 to the present. New York, 2011.

BORSDORF, Ulrich. Industriekultur und Geschichte. In: Forum Industriedenk- 
malpflege und Geschichtskultur 1, 2000, pp. 16-19.

BÖSCH, Delia. Ruhrgebiet. Entdeckungsreise Industriekultur. Essen, 2005.

BRADEMANN, Rita et al. Von der Selbst zur Mitarbeiterverwaltung. Die Zeche Carl in Altenessen. Essen, 1989.

BRÜGGEMEIER, Franz-Josef. Leben vor Ort. Ruhrbergleute und Ruhrbergbau 1889-1919. München, 1983.

BRUNE, Walter \& PUMP-UHLMANN, Brune. Centro Oberhausen. Die verschobene Stadtmitte. Ein Beispiel verfehlter Stadtplanung. Wiesbaden, 2009.

BUDDENSUEG, Tilmann. Industriekultur. Berlin, 1979.

BUSCHMANN, Walter. Zechenanlagen in Essen. In: Denkmalpflege im Rheinland 2:1, 1985, pp. 12-17.

- - D. Denkmäler des Aachener Steinkohlenreviers. In: Denkmalpflege im Rheinland 9:4, 1992, pp. 97-107.

(ed.). Koks - Gas - Kohlechemie. Geschichte und gegenständliche Überlieferung der Kohleveredelung. Essen,1993.

- Zechen und Kokerein im rheinischen Steinkohlebergbau. Berlin, 1998.

Wie Zollverein ein Denkmal wurde. In: Forum Industriedenkmalpflege und Geschichtskultur 1, 2002, pp. 31-36.

CLASSEN, Ludger (ed.). In Zechen, Bahnhöfen und Lagerhallen: zwischen Politik und Kommerz - soziokulturelle Zentren in Nordrhein-Westfalen. Essen, 1989.

CORNELIßEN, Christoph. Historische Identitätsbildung im Bindestrichland Nordrhein-Westfalen (Schriften der Stiftung Bibliothek des Ruhrgebiets). Essen, 2008.

DITTMAR, Jakob. Inszenierte Industrie in der postindustriellen Stadt. Vom Umgang mit stillgelegten Industrieanlagen. Essen, 2002 (Dissertação, Ruhr-Universität Bochum).

DÜRR, Heiner \& GRAMKE, Jürgen (eds.).Erneuerung des Ruhrgebiets. Regionales Erbe und Gestaltung für die Zukunft. Paderborn, 1993.

EBERT, Ralf. Renaissance of former coal mines: Learning from the Ruhr? In: FAUL, Margaret L. (ed.). On the surface: the heritage of mines and mining. Leeds, 2011.

FARRENKOPF, Michael. Die kokereitechnische Entwicklung in der Bundesrepublik Deutschland. In: BAYERL, Günter (ed.). Braunkohleveredelung im Niederlausitzer Revier. 50 Fahre Schwarze Pumpe. Münster et al., 2009.

FAULENBACH, Bernd Das sozialdemokratische Fahrzehnt. Von der Reformeuphorie zur neuen Unübersichtlichkeit. Die SPD 1969-1982. Bonn, 2011.

FÖHL, Axel. The Palace of Projects oder was ist Industriekultur im Revier? In: Forum 2, 2001, pp. 49-54.

FÜBMANN, Klaus, GRÜTTER, Theo \& RÜSEN, Jörnsen (eds.). Historische Faszination. Geschichtskultur heute. Köln et al., 1994, pp. 3-26.

GANSER, Karl. Zehn Jahre Industriedenkmalpflege und Geschichtskultur - was war vorher und was kommt danach?. In: Forum Industriedenkmalpflege und Geschichtskultur 1, 2005, pp. 13-15.

\& HÖBER, Andrea. Raum für Zukunft: die internationale Bauaustellung Emscher. In: RUDOLPH, Karsten et al. (eds.). Reform and Rhein und Ruhr: Nordrhein-Wesfalens Weg ins 21. Fahrhundert. Bonn, 2000, pp. 66-74.

GLASER, Hermann. Maschinenwelt und Alltagsleben. Industriekultur in Deutschland vom Biedermeier bis zur Weimarer Republik. Frankfurt a.M.,1981. 
Industriekultur. Der anthropologische Aspekt. In: Forum Industriedenkmalpflege und Geschichtskultur 1, 2000, pp. 10-14.

GOCH, Stefan Goch. "Der Ruhrge bietler" - Überlegungen zur Entstehung und Entwicklung des regionalen Bewußtseins im Ruhrgebiet. In: Westfälische Forschungen 47, 1997, pp. 585-620.

Wege und Abwege der Sozialwissenschaft: Wilhelm Brepohls industrielle Volkskunde. In: Mitteilungsblatt des Instituts für soziale Bewegungen 26, 2001, pp. 139-176.

Eine Region im Kampf mit dem Strukturwandel. Bewältigung von Strukturwandel and Strukturpolitik im Ruhrgebiet. Essen, 2002.

GRÜTTER, Theodor. Bausteine der Geschichte - die Route der Industriekultur. Industriekultur als kulturelles Erbe. In: Forum Industriedenkmalpflege und Geschichtskultur 1, 2004, pp. 11-19.

GÜNTER, Roland. Im Tal der Könige. Ein Reisebuch zu Emscher, Rhein und Ruhr. Essen, 1994.

Besichtigung unseres Zeitalters. Industriekultur in Nordrhein-Westfalen. Essen, 2001.

HASSLER, Uta \& KIERDORF, Alexander. Denkmale des Industriezeitalters. Von Geschichte des Umgangs mit der Industriekultur. Tübingen, 2000.

HEINEMANN, Ulrich. Industriekultur: vom Nutzen und Nachteil für das Ruhrgebiet. In: Forum Industriedenkmalpflege und Geschichtskultur 1, 2003, pp. 56-58.

HEMMINGS, Sarah \& KAGEL, Martin. Memory gardens: aesthetic education and political emancipation in the "Landschaftspark Duisburg-Nord",
German Studies Review 33:2 (may 2010), pp. 243-261.

HÜCHERIG, Rotraut. Tourismus im Ruhrgebiet - der Beitrag der Internationalen Bauaustellung Emscher Park. Trier, 1992.

Hochlarmarker Lesebuch: Kohle war nicht alles. 100 fahre Ruhrgebietsgeschichte. Bergarbeiter und ihre Frauen aus Recklinghausen-Hochlarmark haben in Zusammenarbeit mit dem kommunalen Stadtkulturreferat ihre Geschichte aufgeschrieben. Oberhausen, 1981.

HUSE, Norbert. Unbequeme Baudenkmale. Entsorgen? Schützen? Pflegen?. München. 1997.

INTERNATIONALE BAUAUSTELLUNG (IBA) EMSVHER PARK (ed.). Denkschrift Nationalpark Industriekultur im Ruhrgebiet. Gelsenkirchen, 1999.

KILPER, Heiderose. Die Internationale Bauaustellung Emscher Park. Eine Studie zur Steuerungsproblematik komplexer Erneuerungsprozesse in einer alten Industrieregion. Leverkusen, 1999.

KLEINEBERG, Kar. Stillegen - was dann? Ansätze der Ruhrkohle AG. In: HÖLSCHER, Martin (ed.). Das Denkmal als Altlast? Auf dem Weg in die Reparaturgesellschaft. Munich, 1996, pp. 64-69.

KOCKA, Jürgen. Sozialgeschichte in Deutschland seit 1945. Aufstieg, Krise und Perspektiven. Bonn, 2002.

KORTE, Barbara \& PALETSCHEK, Sylvia (eds.). Popular history now and then, international perspectives. Bielefeld, 2012.

KOSELLECK, Reinhart. Zeitschichten. Studien zur Historik. Frankfurt a.M., 2003.)

LANGE, Susanne. Bernd und Hilla Becher: life and work. Boston, 2007.

LÜDKE, Alf. Alltagsgeschichte. Frankfurt and New York, 1989. 
MEHRFELD, Ursula. 14 Standorte und mehr: zur zehnjährigen Arbeit der Stiftung Industriedenkmalpflege und Geschichtskultur. In: Forum Industriedenkmalpflege und Geschichtskultur 1, 2005, pp. 16-19.

- Industriedenkmale - schützen, erhalten, nutzen. In: BUDDE, Reinhold (ed.). Industriedenkmale im Ruhrgebiet, Hamburg, 2009, pp. 50-73.

NELLEN, Dieter. Industriekultur - ein Arbeitsauftrag. In: Forum Geschichtskultur Ruhr 1, 2001, pp. 18-21.

NEUMANN, G. \& WEBER, Wolfhard. Bericht über den ersten Internationalen Kongress zur Erhaltung von industriellen Denkmälern in Ironbridge. In: Technikgeschichte 3, 1973.

NIETHAMMER, Lutz. Lebenserfahrung und kollektives Gedächtnis. Die Praxis des “Oral History”. Frankfurt, 1980.

NOLL, Hans-Peter. Der Bergbau geht die Fläche bleibt. Folgenutzungen ehemaliger Bargbaustandorde. In: Bergbau 11, 2009a, pp. 491-496.

. Brachflächenentwicklung - ein Beitrag zur Nachhaltigkeit. In: Glückauf 145, 2009 b, p. 467.

PARENT, Thomas. Industriekultur ist mehr/Industriekultur und mehr. Überlegungen zur aktuellen Diskussion um Profil und "Identität" des Ruhrreviers. In: Forum Industriedenkmalpflege und Geschichtskultur 1, 2001, pp. 27-31

__ In dustriekultur als Herausforderung. Zum Konzept des Westfälischen Industriemuseums. In: Westfälisches Industriemuseum (ed.). Schätze der Arbeit. 25 Fahre Westfälisches Industriemuseum. Essen, 2004, pp. 13-33.

PAULINIY, Ákos. Industriearchäologie Neue Aspekte der Wirtschafts und Technikgeschichte. Dortmund, 1975.
PROSSEK, Achim. Visuelle Regionsproduktion. Ruhrgebiet im Blick. In: Räume. Zeitschrift für Kulturwissenschaften 2, 2008, pp. 65-75.

REICHER, Christa. Industriekultur gespeicherte Erinnerung und kulturelles Potential. In: QUENZEL, Gudrun (ed.). Entwicklungsfaktor Kultur. Studien zum kulturellen und ökonomischen Potential der europäischen Stadt. Bielefeld, 2009, p. 141-163.

et al. Schichten einer Region. Kartenstücke zur räumlichen Struktur des Ruhrgebiets. Berlin 2011.

REICHERT, Sven. Authentizität und Gemeinschaft. Linksalternatives Leben in den siebziger und frühen achtziger Fahren. Berlin, 2014.

RÖCKNER, Katja. Ausgestellte Arbeit. Industriemuseen und ihr Umgang mit dem wirtschaftlichen Strukturwandel. Stuttgart, 2009.

ROHE, Karl. Regionalkultur, regionale Identität und Regionalismus im Ruhrgebiet: empirische Sachverhalte und theoretische Überlegungen. In: LIPP, Wolfgang (ed.): Industriegesellschaft und Regionalkultur. Untersuchungen für Europa. Köln, 1984, pp. 123-153.

RÜSEN, Jör. Was ist Geschichtskultur? Überlegungen zu einer neuen Art, über Geschichte nachzudenken. In: FÜBMANN, Klaus, GRÜTTER, Theo \& RÜSEN, Jörnsen (eds.). Historische Faszination. Geschichtskultur heute. Köln et al., 1994, pp. 3-26.

\footnotetext{
- Industriedenkmale und Geschichtskultur im Ruhrgebiet. In: Industriedenkmalpflege und Geschichtskultur 2, 1998, p. 4.

SACK, Manfred Sack. Siebzig Kilometer Hoffnung. Die IBA Emscher Park Erneuerung eines Industriegebiets. Stuttgart, 1999.
} 
SCHMENK, Holger. Von der Altlast zur Industriekultur. Der Strukturwandel im Ruhrgebiet am Beispiel der Zinkfabrik Altenberg. Bottrop, 2009.

SCHRUMPF, Heinz \& BUDDE, Rüdiger (eds.). Gibt es noch ein Ruhrgebiet? Wissenschaftliche Untersuchungen. Essen, 2001.

SCHWARK, Jürgen (ed.). Tourismus und Industriekultur. Vermarktung von Technik und Arbeit. Berlin, 2004.

SCHWARZ, Angela. Industriekultur, Image, Identität. Die Zeche Zollverein und der Wanel in den Köpfen. Essen, 2008.

SIEVERT, Thomas. Denkmal und künstlerische Verfremdung. In: HÖBER, Andrea \& GANSER, Karl Ganser (eds.). IndustrieKultur: Mythos und Moderne im Ruhrgebiet, 1999, pp. 26-28.

SLOTTA, Delf. Das industrielle Erbe als Chance für Wirtschaft und Kultur. In: Bergmannskalender, 2001, p. 48.

SLOTTA, Rainer. Einführung in die Industriearchäologie. Darmstadt, 1982.

SPETHMANN, Hans. Das Ruhrgebiet im Wechselspiel von Land und Leuten, Wirtschaft, Technik und Politik, 2 Bde. Berlin, 1933.

STURM, Hermann. Industriearchitektur als Kathedrale der Arbeit. Geschichte und Gegenwart eines Mythos. Essen, 2007.

SUHRBIER, Hartwig. Weg vom Aschenputtel-Image. Zur veränderten Wahrnehmung von Bauten der Industrie und Sozialgeschichte im Ruhrgebiet. In:
BARBIAN, Jan-Pieter \& HEID, Ludger (eds.): Die Entdeckung des Ruhrgebiets. Das Ruhrgebiet in Nordrhein-Westfalen 1946-1996. Essen, 1997, pp. 246-258.

TENFELDE, Klaus. Sozialgeschichte der Bergarbeiterschaft an der Ruhr im 19. Fahrhunder. Bonn, 1977.

Geschichtskultur im Ruhrgebiet. In: Gerverkschaftliche Monatshefte 47, 1996, pp. 240-253.

\& URBAN, Thomas (eds.). Das Ruhrgebiet. Ein historisches Lesebuch, vol 1 \& 2. Essen, 2010.

TIGGEMAN, Rolf. Strukturwandel im Ruhrgebiet und Industriekultur. Der Beitrag der Landesentwicklungsgesellschaft und der Grundstücksfonds Ruhr/NRW - Versuch einer Bilanz. In: BUSCHMANN, Walter (ed.). Wischen Rhein-Ruhr und Maas. Pionierland der Industrialisierung - Werkstätte der Industriekultur. Essen 2013, pp. 195-209.

TILMANS, Karin, VAN VREE, Frank \& WINTER, Jay. Performing the past: memory, history and identity in modern Europe. Chicago, 2010.

URBAN, Thomas. Visionen für das Ruhrgebiet. IBA Emscher Park. Konzepte Projekte - Dokumentation. Essen, 2008.

WEBER, Wolfhard Von der. Industriearchäologie über das industrielle Erbe zur Industriekultur. In: TROITSCH, Ulrich \& WOHLAUF, Gabriele (eds.). Technik-Geschichte. Historische Beiträge und neuere Ansätze. Frankfurt, 1980.

\section{Resumo}

A representação da identidade regional na região do Ruhr, na Alemanha, assenta-se predominantemente no patrimônio industrial. Desde a década de 1960, ao longo da transição em curso da indústria pesada para um cenário pós-industrial, o Ruhr conheceu um movimento para preservar os objetos 
históricos associados à sua indústria de carvão e aço. Vindo de baixo, o movimento de defesa do patrimônio industrial tornou-se um fenômeno dominante no Ruhr. O panorama conciso aqui apresentado das mais importantes evoluções históricas do patrimônio industrial no Ruhr cobre 1) as origens do patrimônio industrial, 2) a consagração do patrimônio industrial durante a desindustrialização do Ruhr e 3) as tendências e debates recentes na região.

Palavras-chave: patrimônio industrial; desindustrialização; identidade regional.

\begin{abstract}
The representation of regional identity in Germany's Ruhr region is predominantly based on industrial heritage. Since the 1960s, in the course of its ongoing transition from heavy industry to a postindustrial landscape, the Ruhr has experienced a movement to preserve the historical objects associated with its coal and steel industry. While this had initially been a movement from below, industrial heritage has become a mainstream phenomenon in the Ruhr. This concise overview of the most important developments in the history of industrial heritage in the Ruhr covers 1) the origins of industrial heritage in the Ruhr, 2) the mainstreaming of industrial heritage during the Ruhr's deindustrialization, and 3) the recent developments and controversies in the region.

Keywords: industrial heritage; deindustrialization; regional identity.
\end{abstract}

\title{
Résumé
}

La représentation de l'identité régionale de la région du Ruhr, en Allemagne, repose surtout sur le patrimoine industriel. Depuis les années 1960, au long de la transition de l'industrie lourde vers un paysage post-industriel, le Ruhr a connu un mouvement voué à la préservation des objets historiques associés à son industrie houillère et d'acier. D'abord un mouvement venu d'en bas, la défense du patrimoine industriel est devenue un phénomène dominant au Ruhr. L'exposition succinte ici présentée des plus importantes étapes historiques du patrimoine industriel du Ruhr recouvre 1) les origines du patrimoine industriel, 2) la consolidation du patrimoine industriel au long de la désindustrialisation du Ruhr et 3) les développements et les débats récents dans la région.

Mots-clés: patrimoine industriel; désindustrialisation; identité régionale. 